\title{
Comparative study on quality of scanned images from varying materials and surface conditions of standardized model for dental scanner evaluation
}

\author{
Ju-Hee Park', Jeong-Hwan Seol', Jun Jae Lee', Seung-Pyo Lee², Young-Jun Lim* \\ 'Department of Prosthodontics and Dental Research Institute, School of Dentistry, Seoul National University, Seoul, Republic \\ of Korea \\ 2Department of Oral Anatomy, School of Dentistry, Seoul National University, Seoul, Republic of Korea
}

Purpose: The purpose of this study is to evaluate the image acquisition ability of intraoral scanners by analyzing the comprehensiveness of scanned images from standardized model, and to identify problems of the model. Materials and Methods: Cast models and 3D-printed models were prepared according to international standards set by ISO12836 and ANSI/ADA no. 132, which were then scanned by model scanner and two different intraoral scanners (TRIOS3 and CS3500). The image acquisition performance of the scanners was classified into three grades, and the study was repeated with varying surface conditions of the models. Results: Model scanner produced the most accurate images in all models. Meanwhile, CS3500 showed good image reproducibility for angled structures and TRIOS3 showed good image reproducibility for rounded structures. As for model ingredients, improved plaster model best reproduced scan images regardless of the type of scanner used. When limited to 3D-printed model, powdered surface condition resulted in higher image quality. Conclusion: When scanning structures beyond FOV (field of view) in standardized models (following ISO12836 and ANSI/ADA 132), lack of reference points to help distinguish different faces confuses the scanning and matching process, resulting in inaccurate display of images. These results imply the need to develop a new standard model not confined to simple pattern repetition and symmetric structure. (J Dent Rehabil Appl Sci 2018;34(2):104-15)

Key words: international standard model; intraoral scanner; model scanner; accuracy; digital impression

\section{서론}

아날로그 시대에서 디지털 시대로의 변화와 기술의 발 전은 치과영역에서의 치과 보철물 제작 시스템의 변화에 도 많은 영향을 미치고 있다. 최근까지 치과보철물의 제 작은 아날로그 방식으로 인상을 채득하여 모형을 직접 제작하는 작업방식에 의존해왔다. 이러한 시스템은 지 난 수십 년간 이용되어 왔으며, 현재까지도 많은 부분에 서 이용되고 있다. 하지만 이러한 수작업에 의존하는 방

*Correspondence to: Young-Jun Lim

Professor, Department of Prosthodontics and Dental Research Institute, School of Dentistry, Seoul National University, 101, Daehak-ro, Jongno-gu, Seoul, 03080, Republic of Korea

Tel: +82-2-2072-2940, Fax: +82-2-2072-3860, E-mail: limdds@snu.ac.kr

Received: April 2, 2018/Last Revision: April 23, 2018/Accepted: May 8, 2018
식은 기공물 제작과정에서 개인의 역량차이, 수작업에 따른 오차 등과 같은 여러 가지 요인에 의해 최종보철물 의 품질이 일정하지 않다는 단점들이 제기되고 있다. 이 러한 단점들을 보완하기 위해 1970년대초 Duret 등 ${ }^{1}$ 의 여러 연구자들에 의해 소개된 디지털 Computer-Aided Design/Computer-Aided Manufacture (CAD/CAM) 시 스템에 대한 관심이 높아지고 있는 추세이다. 현재 치과 진료는 기존의 수작업 아날로그방식과 컴퓨터를 이용하 여 치과 보철물을 제작하는 $\mathrm{CAD} / \mathrm{CAM}$ 시스템을 활용

CopyrightC 2018 The Korean Academy of Stomatognathic Function and Occlusion. (c) It is identical to Creative Commons Non-Commercial License. 
하는 디지털방식의 치과진료가 병행되어 이루어지고 있 으며, 점차 디지털방식만을 이용하는 치과진료 및 치과 보철물 제작방식으로 옮겨가고 있는 과도기에 있다고 볼 수 있다..$^{2-4}$ 이러한 디지털 치과 $\mathrm{CAD} / \mathrm{CAM}$ 시스템을 이 루는 구성요소로 구강스캐너를 통한 구강데이터의 3차 원 스캐닝, $\mathrm{CAD}$ 프로그램을 통한 3차원 스캐닝 결과물 의 디자인 그리고 최종보철물을 제작하는 CAM 과정으 로 구성된다고 할 수 있다. 이중 치과 임상과정에서 필요 한 절차로는 구강스캐너를 이용한 구강 데이터 캡처 혹 은 스캐닝을 통한 디지털 인상법이 필수불가결한 절차라 고 할 수 있을 것이다. 디지털 구강 스캐너를 사용하여 구 강데이터를 획득할 경우, 데이터보관 및 재현성이 높아지 고 의료진 간 협력이 용이하게 되어 최종 보철물의 높은 정확도 및 제작 시간의 단축이 가능하게 된다는 장점이 있다. ${ }^{5-7}$ 이러한 구강스캐너는 장치내의 광학장비를 이용 하여 구강을 스캔하고 이미지를 획득하여 2차원 이미지 를 3차원 형상의 데이터 이미지로 변환하는 장치라고 할 수 있는데, 이러한 과정에서 장비 및 소프트웨어 구동방 식에 따라 최종결과물의 정확도는 달라지게 된다. ${ }^{8-11}$ 이 러한 스캐너의 정확도 차이는 최종 출력된 보철물의 정 확도 및 변연적합도에도 영향을 미치게 된다. 스캔이미 지의 구강 내 정확도 및 재현성이 낮을 경우, 치과 수복 물의 수명에도 영향을 줄 수 있으며 수복물과 치아의 간 극에 의하여 2 차 치아우식증 및 다양한 치주질환의 원인 이 될 수 있다. ${ }^{12-17}$ 그러므로 구강스캐너를 통한 정밀한 3 차원 데이터 이미지 취득은 최종 보철치료의 성패를 좌 우하는 가장 중요한 요소라고 할 수 있을 것이다. ${ }^{18-21}$ 하 지만 구강스캐너 성능을 평가하는 중요한 지표인 스캔 이미지의 정확도 및 재현성을 평가하기 위한 국제적 혹 은 국내적인 가이드라인은 현재 확립되어 있지 않은 상 태이다. 현재 3 차원 스캐너와 관련하여 제정됐거나 개 발 중에 있는 국제표준은 다음과 같다. 모델 스캐너의 정 확도 평가를 위한 국제 표준으로 2015년에 제2판으로 개정된 International Organization for Standardization (ISO) 12836이 있다. ISO 12836 표준은 치과용 CAD/ $\mathrm{CAM}$ 시스템을 위한 디지털 장비의 정확도를 평가하기 위한 표준으로 인레이, 계속가공의치, 및 구형 형태의 표 준시편에 대한 대표적인 길이, 각도 및 반경에 대한 재현 정밀도, 반복정밀도 및 진도를 계산하여 정확도를 평가 하도록 명시 하였다. 하지만, ISO 12836 표준은 모델 스 캐너의 정확도 평가 방법만 명시하고 있을 뿐, 치과 임상 진료에 실질적으로 많이 쓰이고 있는 구강스캐너의 평가
방법은 명시되어있지 않다. ${ }^{22}$ 그리고 미국치과의사협회 표준인 American National Standards Institute (ANSI)/ American Dental Association (ADA) Standard 132번이 있지만, 구강스캐너와 모델스캐너를 구분 짓지 않은 상 태로 규격이 제정되어 있다. ${ }^{23}$ 또한, ANSI/ADA 132번 표준을 기반으로 구강스캐너와 관련하여 현재 개발 중 에 있는 ISO/CD 20896 (Dentistry - Scanning accuracy of hand-held devices for dental chairside CAD/CAM systems) 표준의 경우, 표준으로 제정되기에는 시간이 많 이 걸릴 것으로 예상된다.

따라서, 본 연구는 위에서 언급한 표준모델을 $3 \mathrm{D}$ 프린 터를 이용하여 제작한 후, 각 표준모델의 재료와 표면 상 태에 따라 현재 시판중인 구강스캐너를 이용하여 스캔 한 디지털 스캔 이미지를 분석하여 표준모델의 재료 및 형상이 구강스캔 이미지에 어떠한 영향을 미치는지 알아 보고, 이를 바탕으로 구강 스캐너의 정확도를 평가하기 위해 표준모델이 갖추어야 할 기본요건을 도출하며 새로 운 표준모델 설정을 위한 방향을 제시하고자 한다.

\section{연구 재료 및 방법}

\section{Standard model manufacturing}

ISO 12836 표준에서 제시하고 있는 인레이 형태 시 편과 계속가공의치 형태 시편, 미국치과의사협회 표준 (ANSI/ADA Standard) 132번에서 제시하고 있는 크라 운 형태 시편과 인레이 형태 시편을 평가모델로 채택하 였다. 모델 제작은 CAD 프로그램인 Solidworks 2016 (Dassault Systems, Paris, France)을 사용하여 국제표준 에서 제시하고 있는 설계데이터를 참고하여 디자인하였 으며, stereolitho-graphy (STL) 파일 추출 후 Ultra Violet (UV) 레이저 빛을 광경화성 수지의 표면에 조사하여 적 층 제작 방식의 대형광경화조형기 RS Pro 600 (Shanghai 3D Union Tech, Shanghai, China) 3D 프린터를 이용하 여 $3 \mathrm{D}$ 프린팅 표준 모델을 제작하였다. $3 \mathrm{D}$ 프린팅에 사 용된 재료는 Acrylonitile Poly-Butadiene Styrene (ABS) Plastic (Somos GP Plus 14122, DSM, Shanghai, China) 을 사용하였다. 표준모델의 표면 상태에 따른 비교를 위 해 파우더 처리와 샌드블라스팅 처리를 실시하였다. 파 우더 처리는 IP Scan-Spray (IP-Division, Haimhausen, Germany)를 이용하여 입자가 분사되는 노즐의 끝부분 이 시편에서 40 - $60 \mathrm{~mm}$ 의 거리로 수직으로 위치되게 한 


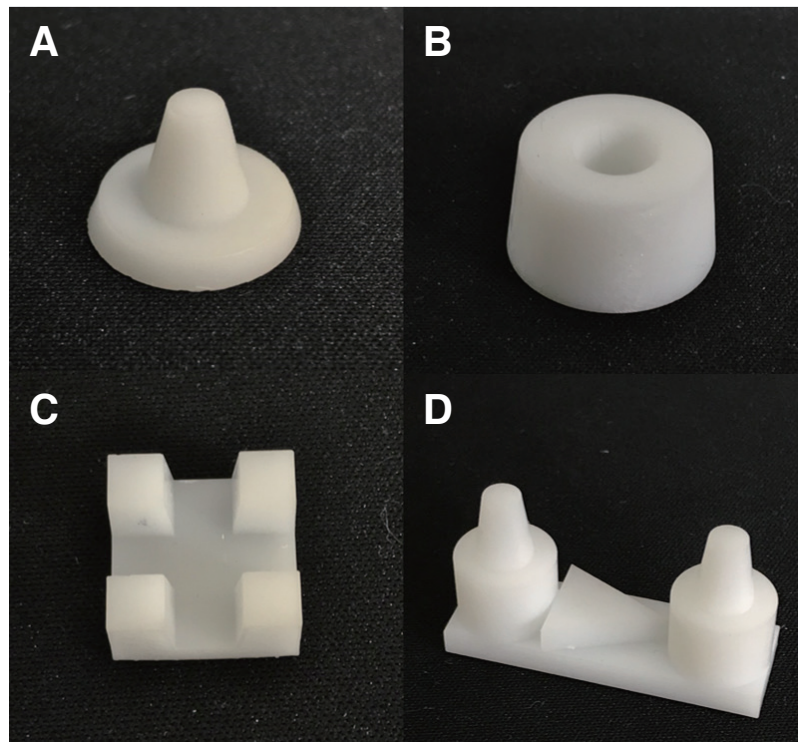

Fig. 1. The standard model image made with the 3D printer. (A) Crown model of ANSI/ADA 132, (B) inlay model of ANSI/ADA 132, (C) inlay model of ISO 12836 and (D) crown/bridge model of ISO 12836.

후 수동으로 균일하게 분사하였으며, 샌드블라스팅 처리 는 Eazimill (Vericom, Anyang, Korea)을 사용하여 입자 가 분사되는 노즐의 끝부분이 시편에서 수직으로 $20 \mathrm{~mm}$ 떨어진 거리에 위치 시킨 후, $50 \mu \mathrm{m}$ (Glass bead)의 입자 를 $4.0 \mathrm{bar}$ 의 압력 하에서 15 초간 분사하여 표면처리를 실시하였다. Fig. 1은 3D 프린터로 제작 한 표준모델을 보여주고 있다.

$3 \mathrm{D}$ 프린터로 제작한 표준모델을 기반으로 하여 음 영 인상재로 정밀성이 뛰어난 Heavy body type의 Putty (Express STD Putty, 3M ESPE, St. Paul, USA)를 이용 해 채득 후 임플란트와 크라운 브릿지 다이의 용도로 쓰 이는 초경석고(Die stone premium, SNOW ROCK, Dk Mungyo Corporation, Gimhae, Korea)를 부어 특상의 강도세기를 가지는 프리미엄 초경석고 표준모델을 제작 하였다. 표준모델의 재질 차이에 따른 각 스캐너의 이미 지의 재현 정도를 비교하기 위해 제작 하였다. Fig. 2는 초경석고로 제작한 표준모델의 이미지를 나타내고 있다.

\section{Apparatus}

본 연구에서는 모델 스캐너로는 IDENTICA Hybrid (MEDIT, Seoul, Korea)를 사용하여 스캔 이미지를 획득

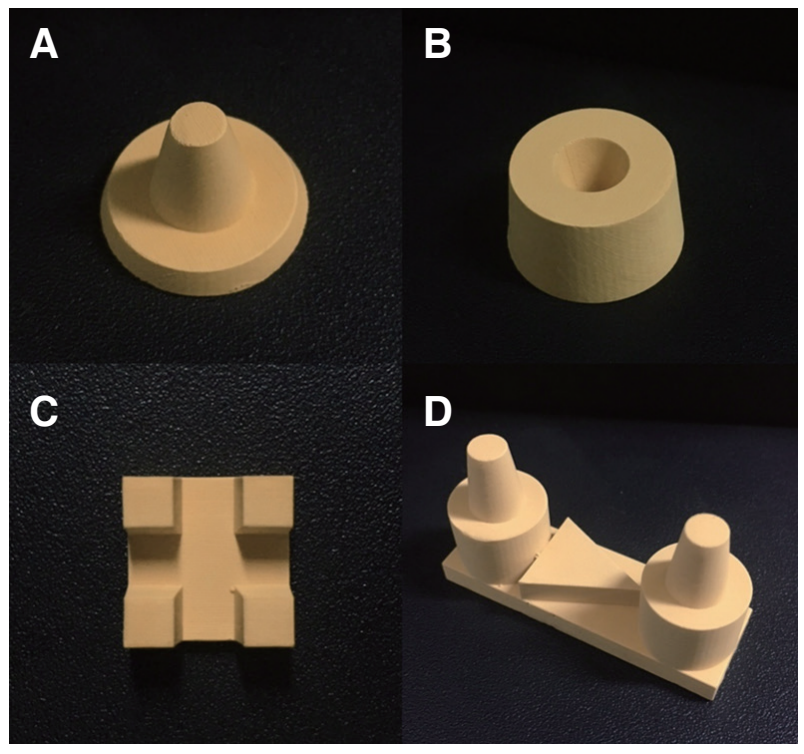

Fig. 2. The standard model image made with the improved stone. (A) Crown model of ANSI/ADA 132, (B) inlay model of ANSI/ADA 132, (C) inlay model of ISO 12836 and (D) crown/bridge model of ISO 12836.

하였고, 구강 스캐너는 구동방식이 서로 다른 두 가지 스 캐너를 사용하였다. 연구에 사용 된 스캐너는 촬영 된 영 상을 순차적으로 결합하여 3차원 형상으로 제작하는 카 메라 방식의 CS3500 (Carestream Health, Atlanta, USA) 과 공초점의 원리에 의해 구동되며 실시간 렌더링 방식을 이용한 동영상 촬영 방식의 TRIOS3 (3Shape, Copenhagen, Denmark)를 이용하여 촬영을 진행하였다. 술자의 숙련도에 따른 스캔 결과 차이를 피하기 위해 9년의 임상 경력과 그 중 4년 이상의 구강스캐너 사용 경험이 있는 1 명의 전담 치위생사가 모든 촬영을 진행하였다. 표준모 델에 대한 스캔은 점착제로 표준 모델 바닥면을 고정 시 킨 뒤 제조사의 지시에 따라 수동으로 스캔하였으며 스 캔이 완료된 후 스캔이 정확하게 되지 않았다고 판단된 부위는 추가로 스캔을 진행하여 5 개의 스캔이미지 파일 을 획득하고, 그 중 가장 많은 영역을 표현하고 있는 최 상의 이미지를 첨부 하였다.

\section{Abbreviation}

실험을 효율적으로 서술하고 용어의 혼선을 막기 위 해 각각의 스캔 이미지의 분류를 약어로 지정하는 작업 을 선행하였다. 예를 들어, 모델스캐너인 IDENTICA 
Table 1. The list of abbreviations used in the experiment

\begin{tabular}{|c|c|c|}
\hline List & Item & Abbreviation \\
\hline \multirow[t]{3}{*}{ Scanner types } & IDENTICA Hybrid & ID \\
\hline & CS3500 & CS \\
\hline & TRIOS3 & TR \\
\hline \multirow[t]{2}{*}{ Materials } & Resin for 3D Printing & $3 \mathrm{D}$ \\
\hline & Improved stone & IS \\
\hline \multirow[t]{3}{*}{ Surface treatments } & No treatment & $\mathrm{NO}$ \\
\hline & Powder & $\mathrm{PO}$ \\
\hline & Sandblast & SB \\
\hline \multirow[t]{4}{*}{ Types of standard models } & Crown form of ANSI/ADA 132 Standard & $\# 1$ \\
\hline & Inlay form of ANSI/ADA 132 Standard & $\# 2$ \\
\hline & Inlay form of ISO 12836 Standard & \#3 \\
\hline & Bridge form of ISO 12836 Standard & $\# 4$ \\
\hline
\end{tabular}

Hybrid 스캐너로 3D 프린팅 한 후 파우더로 표면 처리 한 $\mathrm{ANSI} / \mathrm{ADA} 132$ 표준의 크라운 형태의 시편을 촬영 하여 얻은 스캔 데이터는 ID-3D-PO-\#1로 지칭하였다. Table 1은 전체 실험에 사용 된 약어의 목록을 나타낸다.

\section{Comparison analysis of scanned image}

각각의 스캐너에서 획득 된 스캔 이미지들에 대한 비교 는 실제 표준모델을 비교 기준으로 설정하고 각각의 스 캔 이미지가 실제 표준모델의 형상을 재현하는 정도를 Table 2에서 보는 바와 같이 A, B, C 세 등급으로 분류하 여 정성적으로 비교 분석하였다. 이미지 정합프로그램을 이용한 정확도 분석을 시도하였으나 구강스캐너를 이용 하여 스캔을 실시하였을 때, 표준모델의 원래 형상을 유 지하지 못하고 다른 형태의 스캔이미지가 생성되는 경우 가 다수 발생하여 이미지 정합프로그램을 이용한 비교 분석이 불가능하여 부득이하게 정성적인 평가를 통해 각 스캐너의 이미지 재현 정도를 비교하였다.

Fig. 3 은 본 연구의 전체적인 실험의 흐름을 보여주는 모식도이다.
Table 2. Classification according to image reproduction ratio

\begin{tabular}{cl}
\hline Grade & \multicolumn{1}{c}{ Classification } \\
\hline A & $75 \leq$ Reproduction ratio $(\%) \leq 100$ \\
B & $50 \leq$ Reproduction ratio $(\%) \leq 75$ \\
C & Reproduction ratio $(\%) \leq 50$ \\
\hline
\end{tabular}

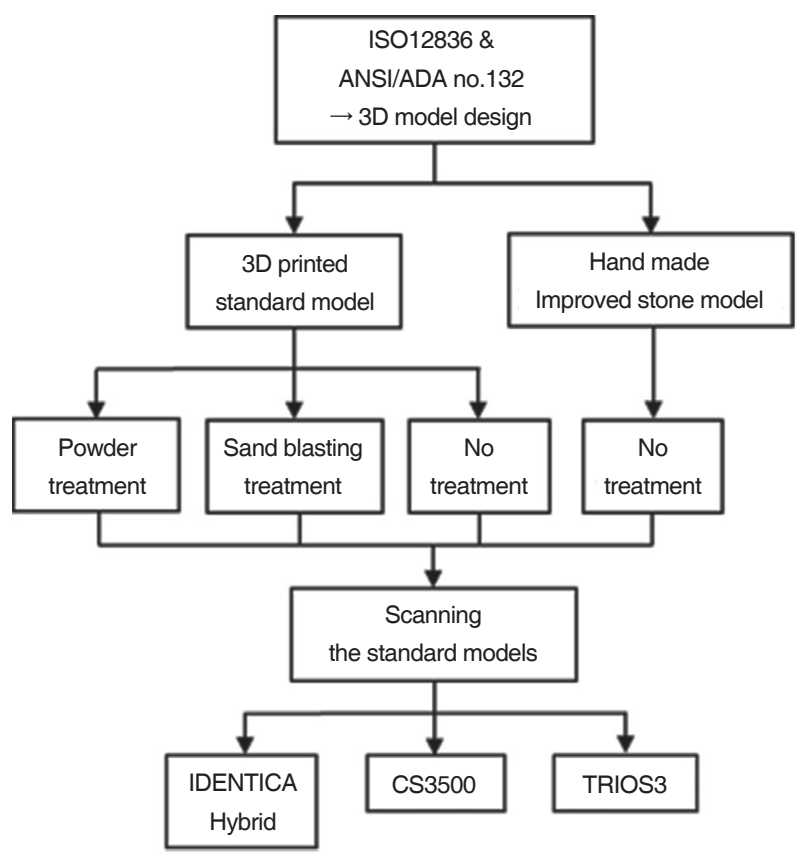

Fig. 3. A schematic diagram of the image acquisition of various scanners according to materials and surface conditions of the standard models. 


\section{결과}

1. 3D printing standard models with no surface treatment

Table 3은 3D 프린터로 표준모델을 제작하고 표면 처 리를 하지 않은 각각의 모델을 스캐너로 촬영한 결과를 보여주고 있다. 모델스캐너의 경우 4 가지 표준모델에 대 해서 전반적으로 거의 완벽한 $\mathrm{A}$ 등급의 스캔 이미지를 획 득할 수 있었다. 하지만 구강스캐너의 경우, $\mathrm{A}$ 등급의 스 캔 이미지는 얻을 수 없었으며 스캐너의 FOV에 포함 되는 크기를 가지는 \#1 모델(CS-3D-NO-\#1, TR-3D-
$\mathrm{NO}$-\#1)에서 두 구강스캐너 모두 B등급의 이미지획득이 가능했고 CS3500의 경우 각진 형태인 CS-3D-NO-\#3, TRIOS3는 둥근 형태의 TR-3D-NO-\#2에서 각각 $\mathrm{B}$ 등 급의 이미지 획득이 가능했다. 그리고 CS3500은 둥근 형 태의 모델(CS-3D-NO-\#2) TRIOS3는 각진 형태의 모델 (TR-3D-NO-\#3)에서 각각 C등급 이하의 저조한 이미지 재현율을 보였다. 두 구강스캐너 모두 고정성 보철물 형 태의 모델(CS-3D-NO-\#4, TR-3D-NO-\#4)인 \#4에서 는 제대로 된 이미지 획득이 불가능했다. Table 4는 각 스 캐너로 획득한 스캔 이미지의 실제모델의 형상 재현 정도 를 나타내고 있다.

Table 3. Scanned image of 3D printing standard models with no surface treatment

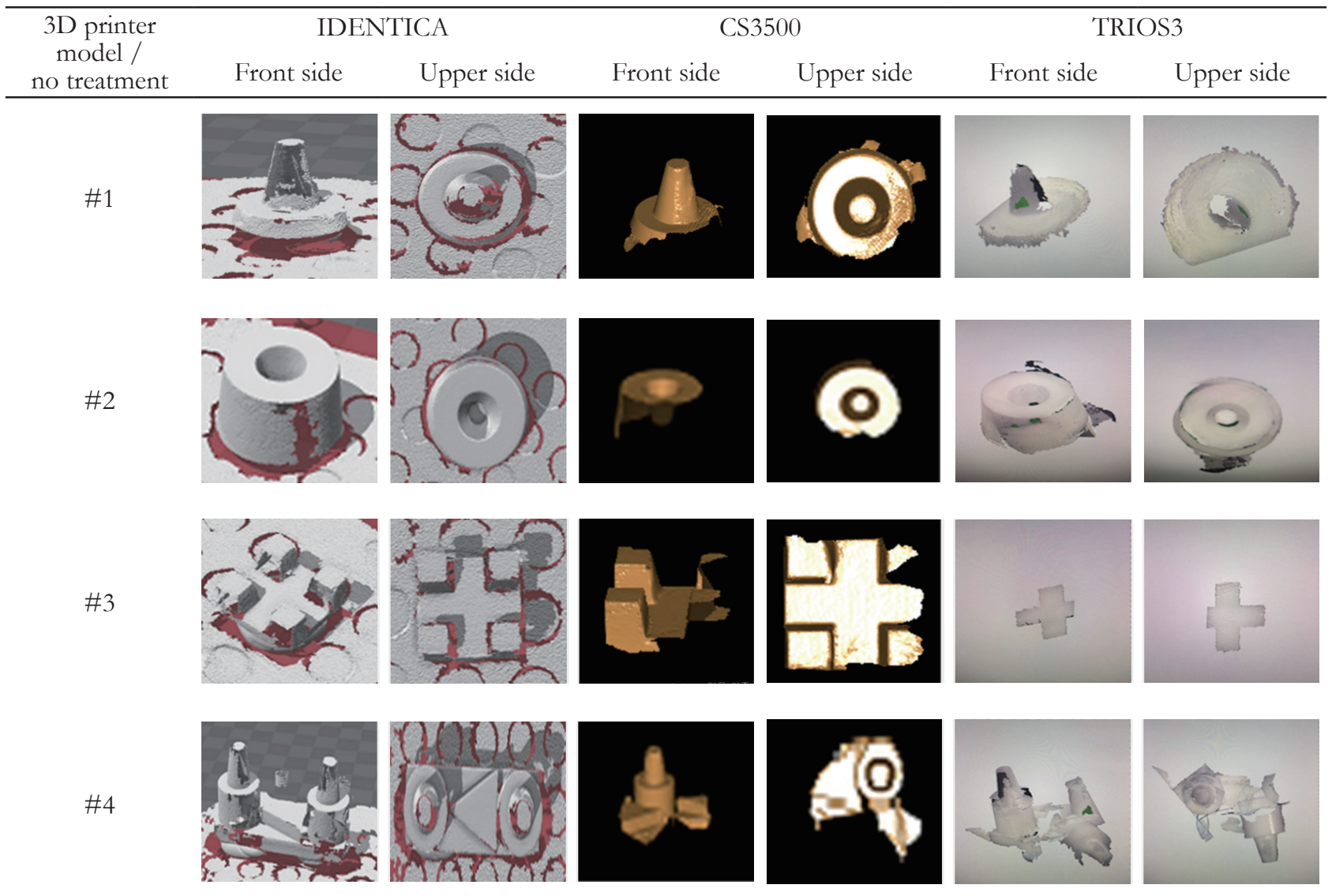

Table 4. Scanned image reproduction ratio of 3D printing standard models with no surface treatment

\begin{tabular}{cc}
\hline Reproduction ratio & Sample \\
\hline A & ID-3D-NO-\#1, ID-3D-NO-\#2, ID-3D-NO-\#3, ID-3D-NO-\#4 \\
B & CS-3D-NO-\#1, CS-3D-NO-\#3, TR-3D-NO-\#1, TR-3D-NO-\#2 \\
C & CS-3D-NO-\#2, CS-3D-NO-\#4, TR-3D-NO-\#3, TR-3D-NO-\#4 \\
\hline
\end{tabular}




\section{Improved stone standard models}

Table 5는 초경석고로 제작한 표준모델을 각각의 스캐 너로 촬영한 결과를 보여주고 있다. 모델스캐너의 경우 4 가지 표준모델에 대해서 완벽한 A등급의 스캔 이미지를 획득할 수 있었다. 구강스캐너의 경우에는 TRIOS3에서 \#1 모델(TR-IS-NO-\#1)에서 유일하게 A등급의 스캔 이
미지는 얻을 수 있었다. 각진 형태인 \#3 인레이 모델(CSIS-NO-\#3, TR-IS-NO-\#3)에서 두 구강스캐너 모두 B등 급의 이미지 재현율을 나타냈다. 고정성 보철물 형태의 모 델(CS- IS-NO-\#4, TR-IS-NO-\#4)은 두 구강스캐너 모 두 C등급 이하의 이미지 재현율을 보이는 것을 알 수 있 다. Table 6은 초경석고 모델을 각 스캐너로 획득한 스캔 이미지의 실제모델의 형상 재현 정도를 나타내고 있다.

Table 5. Scanned image of improved stone standard models with no surface treatment

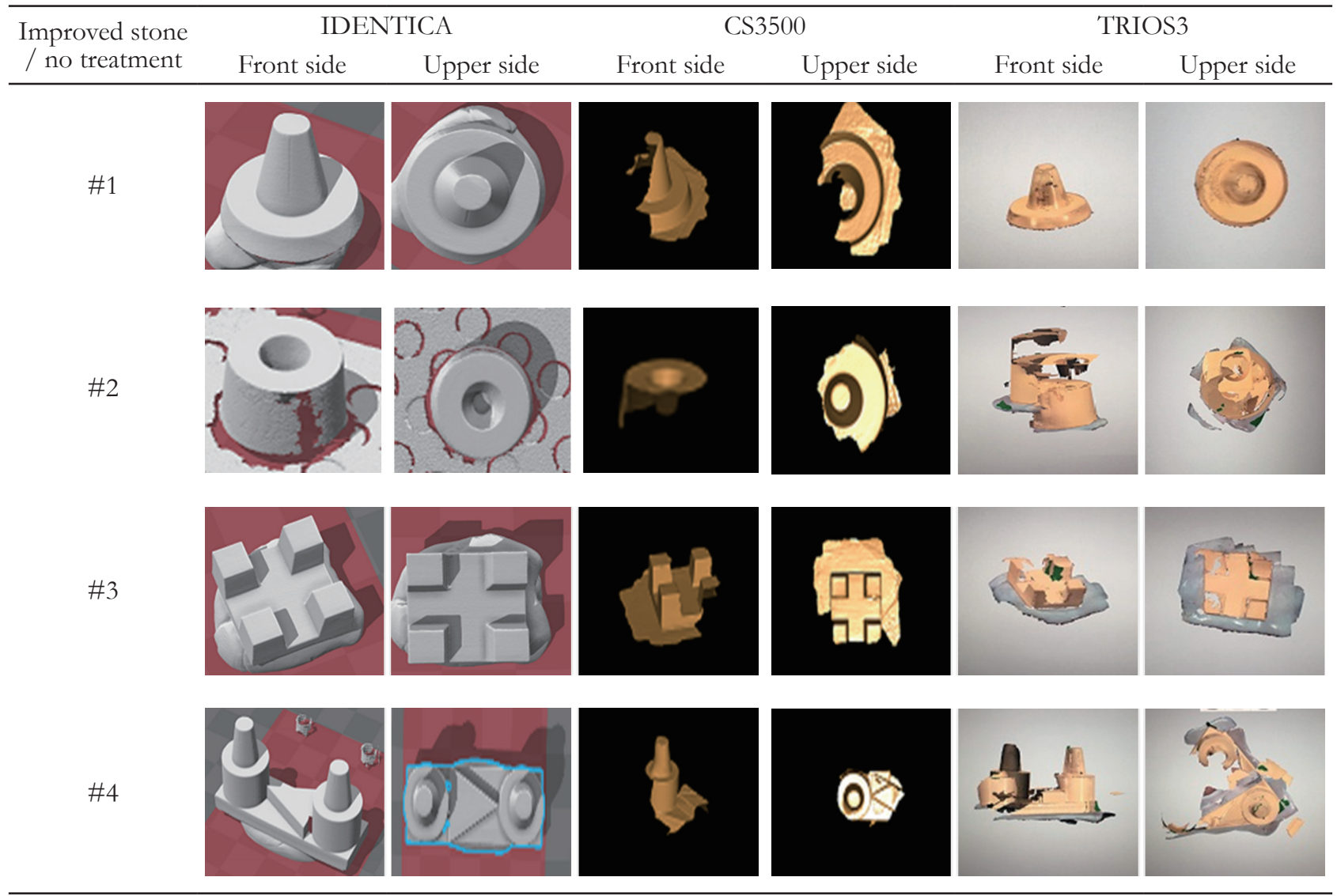

Table 6. Scanned image reproduction ratio of improved stone standard models with no surface treatment

\begin{tabular}{cl}
\hline Reproduction ratio & \multicolumn{1}{c}{ Sample } \\
\hline A & ID-IS-NO-\#1, ID-IS-NO-\#2, ID-IS-NO-\#3, ID-IS-NO-\#4, TR-IS-NO-\#1 \\
B & CS- IS-NO-\#3, TR-IS-NO-\#3 \\
C & CS- IS-NO-\#1, CS- IS-NO-\#2, CS- IS-NO-\#4, TR-IS-NO-\#2, TR-IS-NO-\#4 \\
\hline
\end{tabular}


3. 3D printing standard models with powder treatment

Table 7은 3D 프린터로 표준모델을 제작하고 표면 에 파우더 처리를 한 표준모델을 스캐너로 촬영한 결과 를 보여주고 있다. 모델스캐너의 경우 4가지 표준모델의 표면 처리를 하지 않은 표준모델(ID-3D-NO)에서 보였 던 조금 불완전했던 스캔 이미지와 비교해서 완벽한 $\mathrm{A}$ 등
급의 스캔 이미지를 획득할 수 있었다. 구강스캐너에서 는 CS-3D-PO-\#1, CS-3D-PO-\#3, TR-3D-PO-\#1, TR$3 \mathrm{D}-\mathrm{PO}-\# 2$ 에서 $\mathrm{A}$ 등급의 이미지를 얻을 수 있었으며, $\mathrm{B}$ 등급에 해당하는 표준 모델은 없었고 CS-3D-PO-\#2, CS-3D-PO-\#4, TR-3D-PO-\#3, TR-3D-PO-\#4에서 C 등급의 이미지 재현율을 나타냈다. Table 8 은 각 스캐너 로 획득한 스캔 이미지의 실제모델의 형상 재현 등급을 보여준다.

Table 7. Scanned image of 3D printing standard models with powder treatment

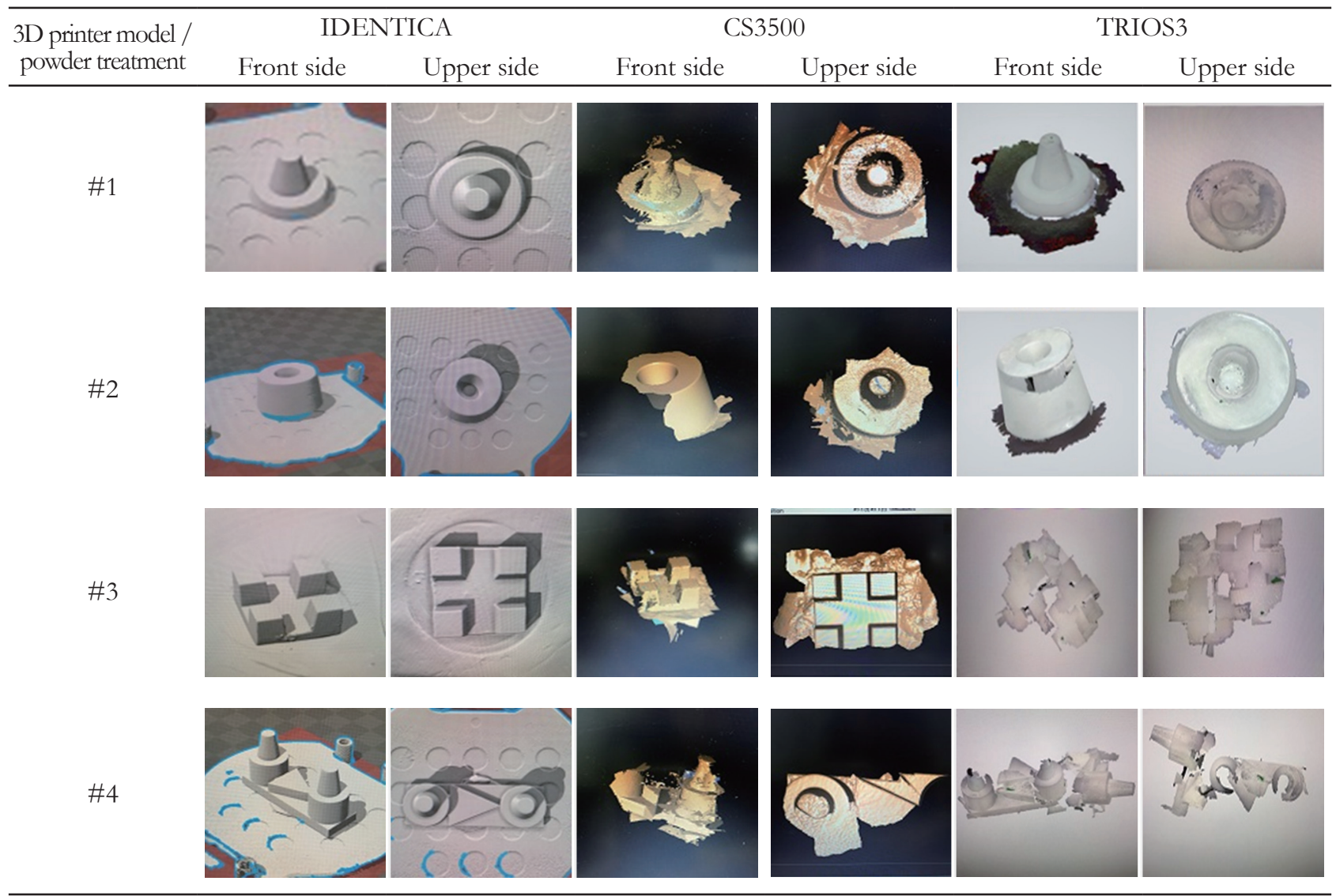

Table 8. Scanned image reproduction ratio of $3 \mathrm{D}$ printing standard models with powder treatment

\begin{tabular}{cl}
\hline Reproduction ratio & \multicolumn{1}{c}{ Sample } \\
\hline A & ID-3D-PO-\#1, ID-3D-PO-\#2, ID-3D-PO-\#3, ID-3D-PO-\#4, \\
B & CS-3D-PO-\#1, CS-3D-PO-\#3, TR-3D-PO-\#1, TR-3D-PO-\#2 \\
C & Not applicable \\
& CS-3D-PO-\#2, CS-3D-PO-\#4, TR-3D-PO-\#3, TR-3D-PO-\#4 \\
\hline
\end{tabular}




\section{3D printing standard models with sand blasting treatment}

Table 9는 3D 프린터로 표준모델을 제작하고 표면에 샌드블라스팅 처리를 한 표준모델을 스캐너로 촬영한 결 과를 보여주고 있다. 모델스캐너의 경우 B등급의 이미지 재현율을 보인 ID-3D-SB-\#3을 제외한 나머지 모델에서
는 완벽한 $\mathrm{A}$ 등급의 스캔 이미지를 획득할 수 있었다. 구 강스캐너에서는 CS-3D-SB-\#3, TR-3D-SB-\#1, TR-3D$\mathrm{SB}-\# 2$ 에서 $\mathrm{B}$ 등급의 이미지를 얻었으며, CS-3D-SB-\#1, CS-3D-SB-\#2, CS-3D-SB-\#4, TR-3D-SB-\#3, TR-3D$\mathrm{SB}-\# 4$ 에서는 $\mathrm{C}$ 등급의 낮은 이미지 재현율을 보였다. Table 10은 각 스캐너로 획득한 스캔 이미지의 실제모델 형상 재현 등급을 보여준다.

Table 9. Scanned image of 3D printing standard models with sand blasting treatment

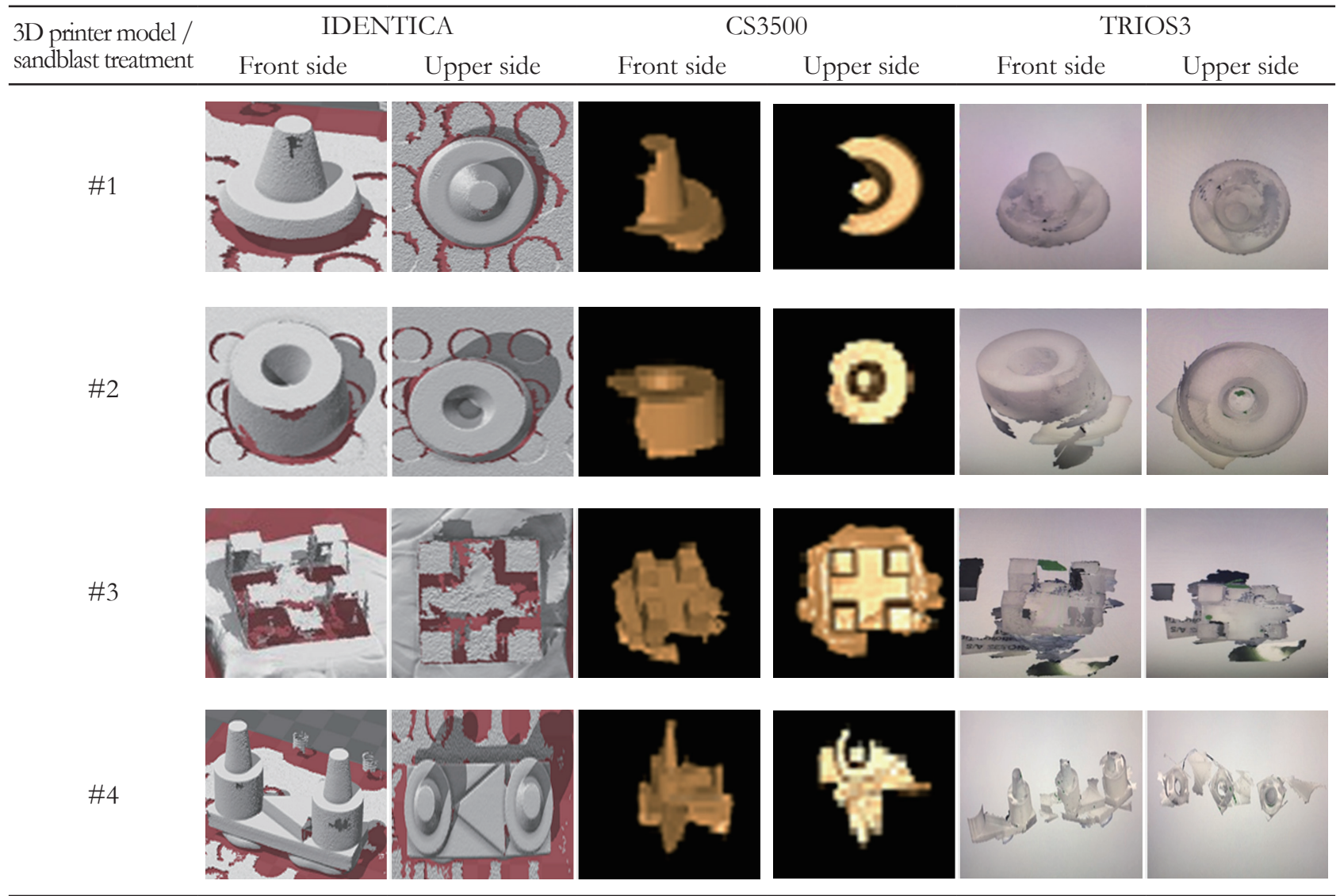

Table 10. Scanned image reproduction ratio of 3D printing standard models with sand blasting treatment

\begin{tabular}{cl}
\hline Reproduction ratio & \multicolumn{1}{c}{ Sample } \\
\hline A & ID-3D-SB-\#1, ID-3D-SB-\#2, ID-3D-SB-\#4 \\
B & ID-3D-SB-\#3, CS-3D-SB-\#3, TR-3D-SB-\#1, TR-3D-SB-\#2 \\
C & CS-3D-SB-\#1, CS-3D-SB-\#2, CS-3D-SB-\#4, TR-3D-SB-\#3, TR-3D-SB-\#4 \\
\hline
\end{tabular}




\section{고찰}

본 연구에서는 재료 및 표면 상태에 따른 표준모델을 모델스캐너와 구강스캐너로 스캔하여 획득한 스캔 이미 지를 실제 표준모델 형상과 비교하고자 하였다. 모델 스 캐너의 경우 재료 및 표면 상태와 관계없이 샌드블라스 팅 처리를 한 3D 프린터 모델의 \#3(ID-3D-SB-\#3)을 제 외하고는 모든 표준 모델에서 완벽한 스캔 이미지를 획 득할 수 있었다. 이는 ISO 12836과 ANSI/ADA 132의 표준모델 형상이 넓은 $\mathrm{FOV}$ 범위를 가지는 모델스캐너 에서는 제대로 인식되어 $3 \mathrm{D}$ 데이터를 제작 할 수 있다는 것을 의미한다.

하지만 구강스캐너에서는 표준모델의 재질과 표면 상 태, 구강스캐너의 구동방식에 따라서 스캔 이미지 획득 에 차이가 나타나는 것을 알 수 있다. 표준모델을 제작 하는 재료에 따른 결과로 유추해볼 때, 표면의 빛 반사가 발생하는 3D 프린터 모델보다는 초경석고로 만든 표준 모델에서 보다 우수한 스캔 이미지를 획득 할 수 있다는 것을 알 수 있다. 또한, 같은 재질의 $3 \mathrm{D}$ 프린터 모델에서 도 표면 처리를 어떻게 하는가에 따라 상이한 결과를 보 였다. 파우더 표면 처리를 한 표준 모델이 샌드블라스팅 처리를 한 표준 모델보다 우수한 스캔 이미지 획득이 가 능하다는 것을 알 수 있었다. 모델스캐너에 비해 FOV 범 위가 좁은 구강스캐너에서는 스캔 범위가 넓은 고정성 보철물 형태의 표준 모델인 \#4를 제대로 인식하지 못한 다는 것을 확인하였다.

구강스캐너의 종류에 따른 스캔 이미지 재현율의 차이 는 다음과 같다. CS3500의 경우 각진 형태의 구조를 가 지는 $\mathrm{ANSI} / \mathrm{ADA} 132$ 표준의 \#3 인레이 모델의 형상을 잘 반영하였고 둥근 형태의 ISO12836 표준의 모델(\#1, \#2)은 제대로 표현하지 못했다. TRIOS3는 둥근 형태의 모델인 ISO12836 표준의 \#1 크라운 모델의 형상을 제 대로 인식하였지만 각진 형태의 ANSI/ADA 132 표준의 \#3 인레이 모델은 제대로 표현하지 못한다는 것을 본 연 구의 결과로 알 수 있었다.

두 구강스캐너의 사양에서 가장 큰 차이는 $\mathrm{FOV}$ 와 화 면 캡처 방식을 들 수 있다. 첫 번째 FOV의 경우, TRIOS3는 $26 \mathrm{~mm} \times 23 \mathrm{~mm}$ 이고 CS3500은 $16 \mathrm{~mm} \times 19$ $\mathrm{mm}$ 와 $12 \mathrm{~mm} \times 9 \mathrm{~mm}$ 를 가지고 있다고 알려져 있다. 비 교적 큰 FOV를 가지는 TRIOS3의 경우 작은 크기의 \#1 크라운 모델을 넓은 FOV를 바탕으로 한 번에 전체 형상 을 인식할 수 있어서 정확한 이미지를 표현한 것으로 보
이며 CS3500은 좁은 $\mathrm{FOV}$ 의 영향으로 \#1, \#2와 같은 단순 패턴의 반복 및 기준점이 없는 형상을 재현하지 못 한 것으로 판단된다. 두 번째 화면 캡처 방식 차이의 경 우, TRIOS3는 비디오 방식이고 CS3500은 분할상 자동 캡처 방식으로 서로 다른 방식을 택하고 있다. 스캔 결과 중에서 특히 \#3 인레이 모델에서 TRIOS3와 CS3500의 결과가 확연히 나뉘는데 이는 구강스캐너의 화면 캡처 방식의 차이에 기인한다고 여겨진다. CS3500의 경우 \#3 인레이 모델과 같이 각지고 반복적인 패턴의 형상을 스 캔 할 때, 비교적 좁은 FOV와 분할상 자동 캡처 방식의 결합으로 단순해 보이는 형상의 모델에서 적절한 기준점 을 찾아내어 완벽한 형상의 재현은 아니지만 비디오 방 식의 TRIOS3 보다 우수한 스캔 이미지를 얻을 수 있었 다고 판단된다. 본 연구에서 구강스캐너를 통한 스캔 시, 표준모델의 원래 형상을 유지하지 못하고 다른 형태의 스캔이미지가 생성되는 경우가 다수 발생하여 이미지 정 합프로그램을 이용한 정량적 비교분석이 불가능하여 부 득이하게 정성적인 평가를 통해 각 스캐너의 이미지 재현 정도를 비교한 것은 본 연구의 아쉬운 점이라 할 수 있겠 다.

$\mathrm{ISO}$ 와 ANSI에서 제시하는 표준 모델은 구강 내 존재 하는 실제 치아와 비교하면 해부학적 구조를 가지고 있 지 않으며 단순한 패턴의 반복, 한 면에 있어서 반복되는 원형이거나 각진 형태의 대칭구조를 가지고 있다는 것을 알 수 있다. 이러한 구조는 좁은 FOV를 가지는 구강스 캐너로 표준 모델을 스캔 할 때 서로 다른 면 혹은 다른 구조물이라는 것을 구분하는 기준점이 불분명하게 되어 연속적인 스캔동작과 이미지 정합 과정에서 차이를 구분 해 내지 못하고 최종 정합 시 오류를 일으켜 이미지 품질 에 악영향을 미친다고 판단된다. 치과 임상용 스캐너의 목적으로 개발된 구강스캐너의 특성상 각기 다른 형상을 띄고 있는 치아의 모습을 재현하기 위해 고안되었기 때 문에 기존의 표준 모델을 스캔 할 때 이러한 오류가 발생 한다고 여겨지며 이러한 단점을 극복할 수 있는 새로운 표준모델의 개발이 필요하다고 여겨진다.

\section{결론}

본 연구를 통해 현재 스캐너의 정확도 평가를 위해 제 정되었거나 추진 중에 있는 국제표준모델은 단순한 패턴 의 반복 및 대칭 구조를 가지고 있어서 스캐너의 정확도 평가, 특히 구강스캐너의 평가를 위해서는 부적합한 모 
델이라는 것을 알 수 있었다. 구강스캐너의 정확도를 하 기 위한 새로운 모델은 단순한 구조이지만 비대칭적이고 일정한 패턴을 가지지 않는 구조이어야 할 것이고 구강 스캐너의 FOV 안에 포함될 수 있는 적절한 크기를 가져 야 한다는 것을 발견하였다. 현재 이러한 결과를 바탕으 로 본 연구실에서는 다양한 형태, 크기의 모델을 디자인 하여 실험을 진행하고 있는 중에 있다. 결과적으로 새로 운 형태의 표준 싱글 모델을 개발하고 이를 더욱 발전시 켜 싱글 모델뿐만 아니라 고정성 보철물 모델, 전악 모델 을 반영하고 구강스캐너로 스캔을 할 수 있는 표준모델 이 제시되어야 할 것이다.

\section{Acknowledgements}

본 연구는 산업통상자원부의 지원을 받아 실시하였습 니다(No.10048888).

This material is based upon work supported by the Ministry of Trade, Industry \& Energy (MOTIE, Korea) under Industrial Technology Innovation Program (No.10048888).

\section{ORCID}

Ju-Hee Park https://orcid.org/0000-0001-9251-5287 Jeong-Hwan Seol https://orcid.org/0000-0003-3719-4681 Jun Jae Lee https://orcid.org/0000-0002-5496-0168 Seung-Pyo Lee https://orcid.org/0000-0002-0103-6705 Young-Jun Lim https://orcid.org/0000-0003-2504-9671

\section{References}

1. Miyazaki T, Hotta Y, Kunii J, Kuriyama S, Tamaki Y. A review of dental CAD/CAM: current status and future perspectives from 20 years of experience. Dent Mater J 2009;28:44-56.

2. Schleyer TK. Digital dentistry in the computer age. J Am Dent Assoc 1999;130:1713-20.

3. van Noort R. The future of dental devices is digital. Dent Mater 2012;28:3-12.

4. Davidowitz G, Kotick PG. The use of CAD/CAM in dentistry. Dent Clin North Am 2011;55:559-70.

5. Murad SM, Al-Mulla A. Accuracy of measurements made on digital and study models (A comparative study). MDJ 2010;7:71-82.

6. Patzelt SB, Lamprinos C, Stampf S, Att W. The time efficiency of intraoral scanners: an in vitro comparative study. J Am Dent Assoc 2014;145:54251.

7. Syrek A, Reich G, Ranftl D, Klein C, Cerny B, Brodesser J. Clinical evaluation of all-ceramic crowns fabricated from intraoral digital impressions based on the principle of active wave front sampling. J Dent 2010;38:553-9.

8. Choi JH, Lim YJ, Lee WJ, Han JS, Lee SP. Review of recent developments for intra-oral scanners. J Dent Rehabil Appl Sci 2015;31:112-25.

9. Lee JJ, Park JY, Bae SY, Jeon JH, Kim JH, Kim WC. Evaluation of the Model Accuracy according to Three Types of Dental Scanner. J Dent Hyg Sci 2015;15:226-31.

10. Schepke U, Meijer HJ, Kerdijk W, Cune MS. Digital versus analog complete-arch impressions for singleunit premolar implant crowns: Operating time and patient preference. J Prosthet Dent 2015;114:403-6.

11. Reddy MS, Mayfield-donahoo T, Vanderven FJ, Jeffcoat MK. A comparison of the diagnostic advantages of panoramic radiography and computed tomography scanning for placement of root form dental implants. Clin Oral Implants Res 1994;5:22938.

12. Abdel-Azim T, Rogers K, Elathamna E, Zandinejad A, Metz M, Morton D. Comparison of the marginal fit of lithium disilicate crowns fabricated with CAD/CAM technology by using conventional impressions and two intraoral digital scanners. J Prosthet Dent 2015;114:554-9.

13. Ueda K, Beuer F, Stimmelmayr M, Erdelt K, Keul C, Güth JF. Fit of 4-unit FDPs from CoCr and zirconia after conventional and digital impressions. Clin Oral Investig 2016;20:283-9.

14. Nedelcu RG, Persson AS. Scanning accuracy and precision in 4 intraoral scanners: an in vitro comparison based on 3-dimensional analysis. J Prosthet Dent 2014;112:1461-71.

15. Patzelt SB, Emmanouilidi A, Stampf S, Strub JR, Att W. Accuracy of full-arch scans using intraoral scanners. Clin Oral Investig 2014;18:1687-94.

16. Patzelt SB, Vonau S, Stampf S, Att W. Assessing 
the feasibility and accuracy of digitizing edentulous jaws. J Am Dent Assoc 2013;144:914-20.

17. Papaspyridakos P, Gallucci GO, Chen CJ, Hanssen S, Naert I, Vandenberghe B. Digital versus conventional implant impressions for edentulous patients: accuracy outcomes. Clin Oral Implants Res 2016;27:465-72.

18. Lee GT, Kim JH, Kim WC, Kim JH. Three-dimensional evaluation on the repeatability and reproducibility of dental scanner-based digital models. J Korean Acad Dent Technol 2012;34:213-20.

19. Yuzbasioglu E, Kurt H, Turunc R, Bilir H. Comparison of digital and conventional impression techniques: evaluation of patients' perception, treatment comfort, effectiveness and clinical out- comes. BMC Oral Health 2014;14:10.

20. Kim JH, Kim KB. Evaluation of dimensional stability of digital dental model fabricated by impression scanning method. J Dent Hyg Sci 2014;14:1521.

21. Kim SH, Kim JH, Kim CK. Reliability and accuracy of digital impression obtained from CS-3500 intraoral scanner. J Dent Hyg Sci 2015;15:673-8.

22. ISO 12836:2015 Dentistry - Digitizing devices for CAD/CAM systems for indirect dental restorations - Test methods for assessing accuracy.

23. ANSI/ADA. Standard No. 132, Scanning accuracy of dental chairside and laboratory CAD/CAM. ADA 132-2015. 


\title{
치과용 스캐너 평가를 위한 국제표준모델의 재료 및 표면 상태에 따른 스캔 영상 결과물 비교 연구
}

\author{
박주희 ${ }^{1}$, 설정환 ${ }^{1}$, 이준재 ${ }^{1}$, 이승표 ${ }^{2}$, 임영준 ${ }^{*}$ \\ ${ }^{1}$ 서울대학교 치의학대학원 치과보철학교실 \\ ${ }^{2}$ 서울대학교 치의학대학원 구강해부학교실
}

목적: 본 연구는 현재 시판되고 있는 구강스캐너를 사용하여 구강스캐너 정확도 평가를 위해 국제표준이 제안하고 있는 모형의 스캔이미지 획득이 가능한 지 분석하고, 이를 통해 표준모델이 가지고 있는 문제점을 파악하는 데 있다.

연구 재료 및 방법: ISO12836과 ANSI/ADA no.132에서 규정하는 국제표준을 참고하여 3D 프린터기를 이용하여 모델 을 제작하였으며, 모델스캐너와 두 가지 구강스캐너를 이용하여 스캔을 하였다. 스캔이미지 획득 정도를 3 등급으로 분 류하여 스캐너의 성능을 비교하였으며, 모델 표면의 상태에 따른 이미지 획득 능력도 비교하였다.

결과: 모델 스캐너가 모든 모델에서 가장 우수한 이미지를 얻을 수 있었으며 TRIOS3는 둥근 형태의 구조물, CS3500은 각진 형태의 구조물에 대한 이미지 재현이 좋은 결과를 보였다. 표준 모델의 표면상태에 따른 스캔이미지 재현에서는 초 경석고 모델이 스캐너 종류와 관계없이 가장 우수하였다. 3D 프린팅 모델의 경우, 표면에 파우더 처리를 한 모델에서 가 장 우수한 스캔이미지를 얻을 수 있었다.

결론: ISO12836과 ANSI/ADA 132의 표준모델의 경우, 구강스캐너의 field of view (FOV)를 벗어나는 구조물을 스캔 할 때 서로 다른 면인 것을 구분하는 기준점이 존재하지 않게 되면 연속적인 스캔 및 정합과정에서 정확한 이미지를 나타 내지 못한다는 것을 알 수 있었다. 그러므로 단순한 패턴의 반복과 대칭구조를 가지지 않는 새로운 표준모델이 필요하다 고 여겨진다.

(구강회복응용과학지 2018;34(2):104-15)

주요어: 국제표준모델; 구강스캐너; 모델스캐너; 정확도; 디지털 인상

*교신저자: 임영준

(03080)서울시 종로구 대학로 101 연건동 서울대학교 치과병원 치과보철학교실

Tel: 02-2072-2940 | Fax: 02-2072-3860 | E-mail: limdds@snu.ac.kr

접수일: 2018년 4월 2일 | 수정일: 2018년 4월 23일 | 채택일: 2018년 5월 8일 